\title{
Silicon Conversion From Bamboo Leaf Silica By Magnesiothermic Reduction for Development of Li-ion Baterry Anode
}

\author{
Silviana Silviana ${ }^{l}$, Wardhana J. Bayu ${ }^{2}$ \\ ${ }^{1}$ Department of Chemical Engineering, Faculty of Engineering, Diponegoro University ,Jl. Prof. Sudarto, Tembalang-Semarang, \\ 50275, Telp/fax: (024)7460058/(024)76480675 \\ ${ }^{2}$ Master Degree of Department of Chemical Engineering, Faculty of Engineering, Diponegoro University, Jl. Prof. Sudarto, \\ Tembalang-Semarang, 50275, Telp/fax: (024)7460058/(024)76480675
}

\begin{abstract}
Silicon ( $\mathrm{Si}$ ) is a promising alternative material for the anode Lithium ion Battery (LIB). Si has a large theoretical capacity about $3579 \mathrm{~mA} \mathrm{hg}-1$, ten times greater than the commercial graphite anode (372 mA hg -1). Bamboo is a source of organic silica (bio-silica). Most part biogenetic content of $\mathrm{SiO}_{2}$ is obtained in bamboo leaves. This paper aims to investigate the synthesis nano $\mathrm{Si}$ from bamboo leaves through magnesiothermic reduction after silica extraction using sol-gel method and to observe nano $\mathrm{Si}$ of bamboo leaf as mixed material for lithium ion baterry. Silica and silicon content was determined using XRF. Silica product has $96,3 \mathrm{wt}$. $\%$ yield of extraction from bamboo leaf, while silicon yield was obtained $61.2 \mathrm{wt}$. \%. The XRD pattern revealed that silica and silicon product were amourphous. The extracted silica and silicon from bambo leaf has spherical shape and agglomerated form. As anoda material for LIB, silicon product achieved 0,002 mAh capacity for 22 cycle.
\end{abstract}

\section{Introduction}

Silicon, the second most common element in the earth's crust have attracted so many attention in the energy storage application because of their high potential capacity. Silicon has been considering most promosing candidate to replace graphite anode. They have large theoretical capacity about $3579 \mathrm{mAh} \mathrm{g}^{-1}$, almost 10 times higher theoretical specific capacity than graphite anode( $372 \mathrm{mAhg}^{-1}$ ) [1]. Silicon usually has obtained from mineral in rock and sand, however, silicon also can be obtained in organic material such as risk husk, bamboo leaf, wheat husk and another agricultural waste.

Bamboo is a source of organic silica (bio-silica). The bamboo absorbs silicic acid from the water and then convert it into $\mathrm{SiO}_{2}$ hydrate in the root branches and leaves [2].Most part biogenetic content of $\mathrm{SiO}_{2}$ is obtained in bamboo leaves. Bamboo leaves have a silica content of $17-23 \%$ by weight, higher than the silica content in rice husk (9.3-13.5\% by weight)[3]. Bamboo leaf ash has a large $\mathrm{SiO}_{2}$ content of $75.90-82.86 \mathrm{wt} \%$ [4] [5].

The sol gel technique mainly used for extracting silica from agricultural material like rice husk [6], sugar cane bagasse [7-8], wheat husk [9], corn cob [10], and wheat staw [11]. The sol-gel process is widely used to produce pure silica particles due to its ability to control the particle size, size distribution and morphology through systematic monitoring of reaction parameters [12].

Silica can be reduced to silicon by using several method: carbothermic reduction, aluminothermic reduction, calciothermic reduction, and magnesiothermic reduction [13]. Conventional carbothermic reduction was usually used by industrial apllication to reducing silica into silicon. Oxygen is removed by reaction sequences of heterogeneous-homogeneous at a temperature of about $3000{ }^{\circ} \mathrm{C}$ [14]. In the present work, magnesium as a reducing agent, was introduced to reduce the reaction temperature until $650^{\circ} \mathrm{C}$ [15]. Silica can be reduced by magnesium (magnesiothermic reduction) to produce silicon through following reaction:

$$
\text { or } \quad \begin{aligned}
2 \mathrm{Mg}(g)+\mathrm{SiO}_{2}(s) & \rightarrow 2 \mathrm{MgO}(s)+\mathrm{Si}(s) \\
& 2 \mathrm{Mg}(s)+\mathrm{SiO}_{2}(s) \rightarrow 2 \mathrm{MgO}(s)+\mathrm{Si}(s)
\end{aligned}
$$

If Mg excess,

$$
2 \mathrm{Mg}(\mathrm{s})+\mathrm{Si}(\mathrm{s}) \rightarrow \mathrm{Mg}_{2} \mathrm{Si}(\mathrm{s})
$$

The formation of $\mathrm{Mg}_{2} \mathrm{Si}$ is affected by the excess $\mathrm{Mg}$ and reduction temperature. Decreasing magnesium amount resulted in decreasing $\mathrm{Mg}_{2} \mathrm{Si}$ and with increasing temperatures at fixed ratio of $\mathrm{Mg}$ to $\mathrm{SiO}_{2}$, the formation of $\mathrm{Mg}_{2} \mathrm{Si}$ increased [16].

Corresponding author: silviana@,che.undip.ac.id 


\section{Experimental Method}

\subsection{Silica Extraction}

Bamboo leaves was collected from Sragen, Central Java To remove alkali impurities, the bamboo leaf were crushed and leached by $1 \mathrm{M} \mathrm{HCl}$ for 2 hours, after washing in water and drying the bambo leaves were calcined at $650^{\circ} \mathrm{C}$ for 2 hours in muffle furnace to remove organic impurities.

Silica was extracted from Bamboo Leaf Ash, (BLA) using sol-gel Method to produce silica xerogel [7]. In this method, $60 \mathrm{ml} \mathrm{NaOH} 2 \mathrm{M}$ were added to $10 \mathrm{~g}$ BLA and boiled for $1 \mathrm{~h}$ with constant stirring to extract the silica and produce sodium silicate solution. The solution were filtered trough whatman No.41. The filtrate solution was sodium silicate, cooled to room temperature and the $\mathrm{pH}$ solution was reduced with $1 \mathrm{~N} \mathrm{HCl}$ to 7.0 under constant stirring to produce silica gels. When the solution gel was formed, it was aged for $18 \mathrm{~h}$. After aging, the soft gel gently broken by adding $100 \mathrm{ml}$ destilled water and centifuged at $3000 \mathrm{rpm}$ to make a slurry. The slurry was filtered and washed. The supernatant was discarded and the gel was dried at 80 at $12 \mathrm{~h}$ to produce white powder silica (xero-gel).

\subsection{Silica Reduction}

Synthesis of silicon from the as-produced silica was conducted by a magnesiothermic reduction process. Silica (xero gel) mixed with magnesium powder with the $\mathrm{SiO}_{2}: \mathrm{Mg}$ ratio of $1: 0,4$. The powder was heated in a furnace under Ar gas flow and held at $650^{\circ} \mathrm{C}$ for 2 hours. After the reaction the powders were immersed in $1 \mathrm{M}$ $\mathrm{HCl}$ solution for 6 hour to remove $\mathrm{MgO}, \mathrm{MgSi}$ and unreacted $\mathrm{Mg}$ [15].

\section{Result And Discussion}

\subsection{Silica Extraction Composition}

The silicas's purity can be determined using XRF method. It shown in table 1, sol-gel method can produced silica with purity of $96.3 \%$ wt. $\%$. The remaining elements include metallic impurities such $\mathrm{K}$, $\mathrm{Ca}, \mathrm{Fe}, \mathrm{Ni}, \mathrm{Cu}, \mathrm{In}, \mathrm{Yb}$. This high yield of silica indicated that during sol-gel extraction, only anmorphous silica was synthesized. Silica dissolved from BLA in sodium hydroxide and produce sodium silicate. The reaction as follows:

$$
x \mathrm{SiO}_{2}+2 \mathrm{NaOH} \rightarrow \mathrm{Na}_{2} \mathrm{O} . \times \mathrm{SiO}_{2}+\mathrm{H}_{2} \mathrm{O}
$$

The sodium silicate solution reacts with hydrochloric acid to produce silica gel. The reaction is:

$$
\mathrm{Na}_{2} \mathrm{O} . \times \mathrm{SiO}_{2}+\mathrm{HCl} \rightarrow \times \mathrm{SiO}_{2}(\text { gel })+\mathrm{NaCl}+\mathrm{H}_{2} \mathrm{O}
$$

The presence of ion $\mathrm{Na}+$ have important rule in this reaction. Interaction between $\mathrm{Na}^{+}$and negatively silicate would speed up the reaction. Ion $\mathrm{Na}+$ promoted the gel formation by screening the surface charge of particles that favors their agregation. [7].

Table 1. Silica product from sol gel method.

\begin{tabular}{|c|c|c|c|c|c|c|c|c|}
\hline Compound & $\mathrm{Si}$ & $\mathrm{K}$ & $\mathrm{Ca}$ & $\mathrm{Fe}$ & $\mathrm{Ni}$ & $\mathrm{Cu}$ & $\mathrm{In}$ & $\mathrm{Yb}$ \\
\hline $\begin{array}{c}\text { Concentrati } \\
\text { on Unit }\end{array}$ & 96.3 & 0.2 & 1.8 & 0.42 & 0.52 & 0.16 & 0.4 & 0.1 \\
\hline
\end{tabular}

The SEM image of silica xerogel BLA was shown in Fig.1. The extracted silica was spherical an agglomerated form. The particle has various size in nano scale.

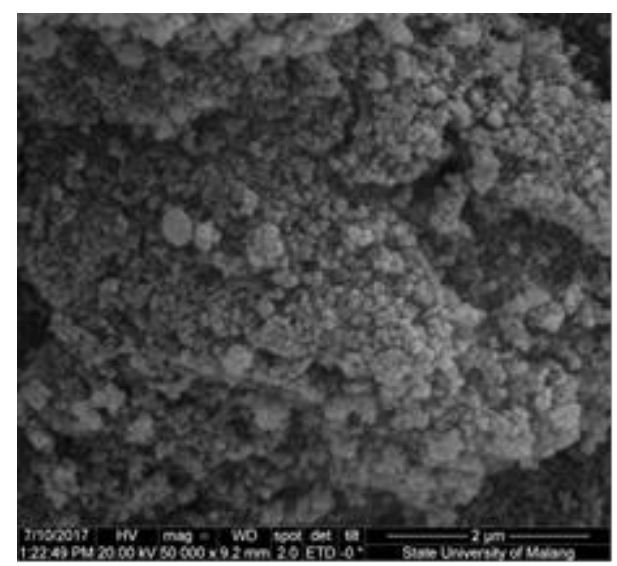

Fig.1. The scanning electron micrograph (SEM) image of silica xerogels from BLA

An XRD pattern of prepared silca gel from bamboo leaf is shown in Fig.2. The diffused peak at $2 \theta=22,6$ indicated that silica gel were solid amorphous [3][6]. It was confirmed by the absence of any ordered crystalline structure. This XRD pattern also proved that sol-gel process completely eliminates most of crystalline structured impurities in $\mathrm{BLA}$, ie $\mathrm{K}_{2} \mathrm{O}, \mathrm{Fe}_{2} \mathrm{O}_{3}, \mathrm{CaO}$ [17].

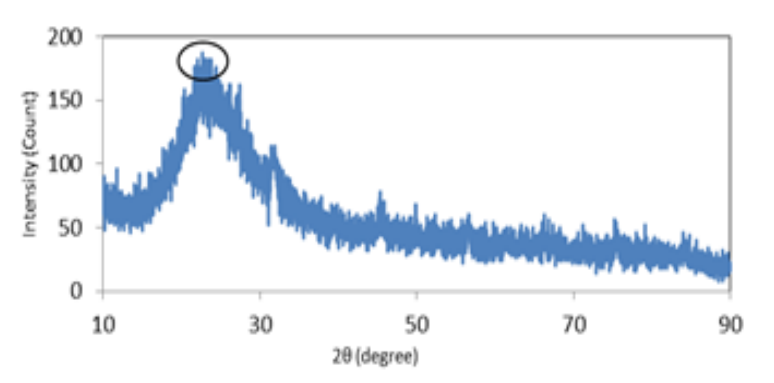

Fig. 2. XRD diagram of Silica BLA

The amorphous, nano scaled silica have many advantages, it can be easily dissolved, have high porosity and high surface area that provide higher activities reaction [18]. 


\subsection{Silicon Reduction}

The component of silicon from magnesiothermic reduction were characterized using XRF. The main component was silicon (61.2\%.wt) and Magnesium (31 $\%$.wt). It was also confirmed from XRD Diffractorams (Fig 3). There is an another strong peak beside of silica that indicate the presence of magnesium.

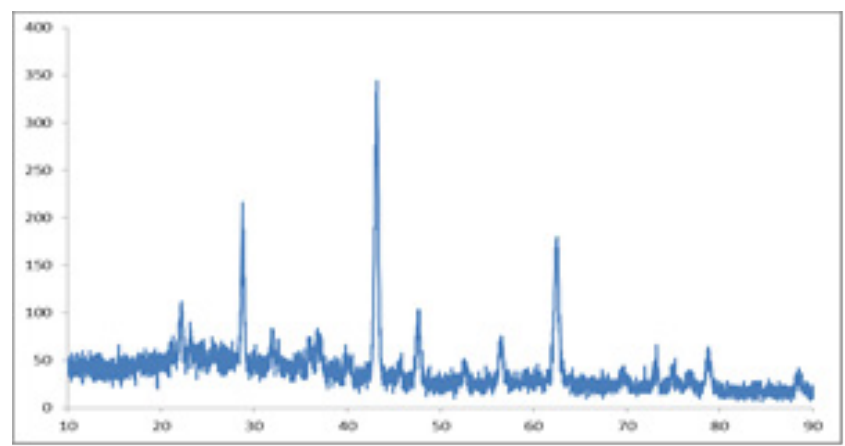

Fig.3. X-ray diffraction pattern of silicon produced from magnesio-thermic reduction.

It is suspected that in this experiment, there was magnesium excess in reaction, and as a result, following Equation 3, the silicon product was reduced [19]. Leaching process method taking big role to obtain high purity silicon. It is need to optimize the condition and variable of leaching process due the low purity silicon product.

From the morphology characterization by using SEM, it was shown in Fig.4., that nano silicon has spherical particle shape and agglomerated. Hence there is no significant difference between silica and silicon product in a term of morphology.

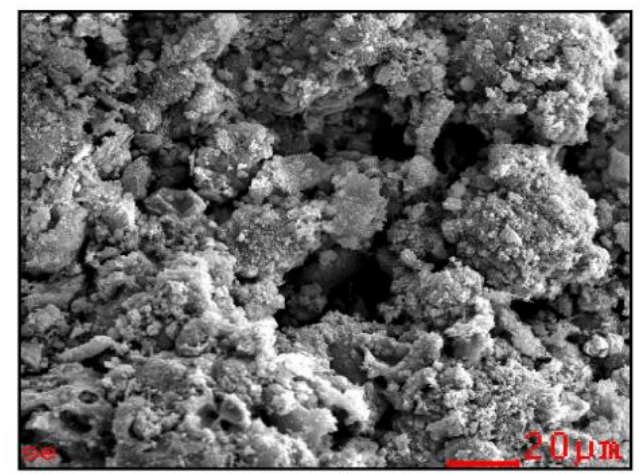

Fig.4. The scanning electron micrograph (SEM) image of silicon product from magnesiothermic reduction

\subsection{Silicon as anoda material for LIB}

Lithum ion batteries performance. with silicon BLA as anoda material was tested by the galvanostatic cycling method. As the result (Fig.6.) the maximum capacity of electroda was $0.002 \mathrm{mAh}$ at 22 cycles.

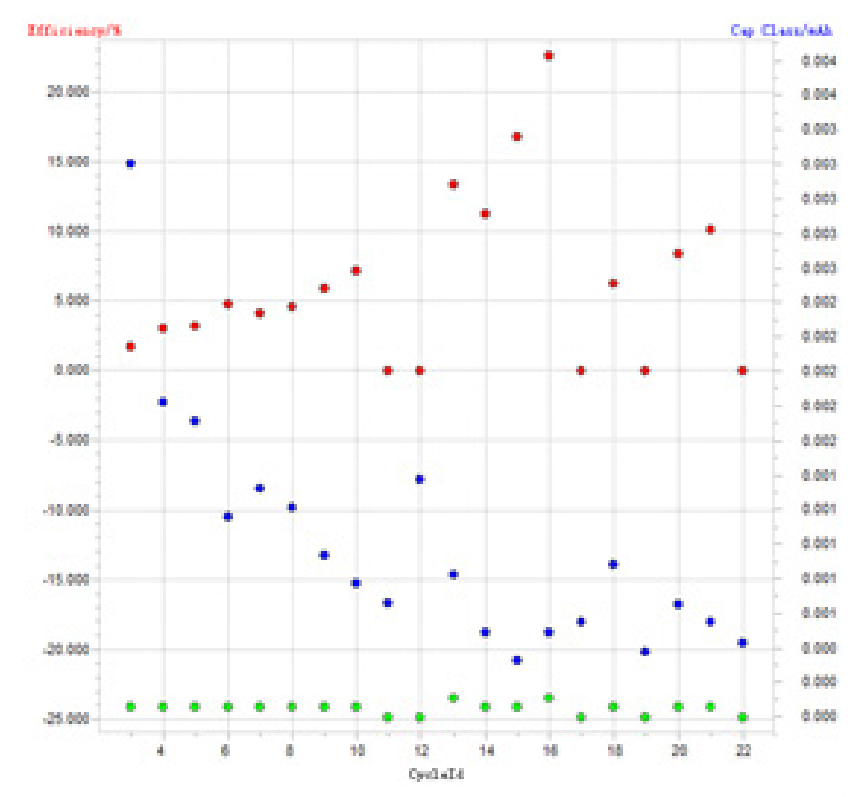

Fig.6. Galvanostatic cycles

The present of $\mathrm{MgO}$ has significant effect for the low electroda capacity. $\mathrm{MgO}$ is insulator material because of its wide band gap $(\sim 7.8$ e), that may decrease the elctroda capacity [20].

\section{Conclusion}

Nano silica has been suscesfully extracted from bamboo leaves by sol gel technique and then reducted into silicon using magnesiothermic reduction. Silica from bamboo leaves has $93.6 \% \%$.wt purity while silicon was $61.2 \%$ .wt. From XRD and SEM analysis reveals that silica and silicon BLA were amorphous with spherical shape and agglomerated form. Silica performance as LIB anoda material was tested using eight channel baterry. The electroda's capacity was $0.002 \mathrm{mAh}$ for 22 cycle.

\section{References}

1. Tian, H., Xin, F., Wang, X., He, W. and Han, W., J. Mater. 1, 3 (2015)

2. Currie, H. and Perry, C., Ann. Bot, 100, 7 (2007)

3. Kow, K. W., Yusoff, R., Aziz, A. R. A. and Abdullah, E. C., J. Non. Cryst. Solids, 386 (2014)

4. Dwivedi, V. N., Singh, N. P., Das, S. S. and Singh, N. B., Int. J. Phys. Sci., 1, 3 (2006)

5. Mohapatra, S., Sakthivel, R., Roy, G. S., Varma, S. and Singh, S. K. Mater. Manuf. Process. 26 (2011)

6. Kamath, S. R. and Proctor, A., Cereal Chem. $\mathbf{7 5}$ (1998)

7. Affandi, S., Setyawan, H., Winardi, S., Purwanto, A., and Balgis, R., Adv. Powder Technol. 20, 5 (2009)

8. Mupa, M., Hungwe, C. B., Witzleben, S., Mahamadi, C., and Muchanyereyi, N., Afr. J. Pure Appl. Chem. 9, 2 (2015) 
9. Javed, S. H., Shah, F. H., and Mansha, M., J. Fac. Eng. Technol. 18, 0092 (2011)

10. Okoronkwo, E. A., Imoisili, P. E., and Olusunle, S. O. O., Chem. Mater. Res. 3, 4 (2013)

11. Patel, K. G., Misra, N. M., and Shettigar, R. R., IJCEA 7, 5 (2016)

12. Rahman, I. A. and Padavettan, V., J. Nanomater. 2012 (2012)

13. Sadique, S. E., Thesis (2010)

14. Aminullah, Rohaeti, E., and Irzaman, Procedia Environ. Sci. 24 (2015)

15. Liu, N., Huo, K., McDowell, M. T., Zhao, J., and Cui, Y., Sci. Rep. 3 (2013)

16. Kalem, T., Thesis (2004)

17. Rani, K. M., Palanisamy, P. N., and Sivakumar, P., Int. J. Adv. Technol. Eng. Sci. 2, 10 (2014)

18. Awizar, D. A., Othman, N. K., Jalar, A., Daud, A. R., Rahman, I. A., and Al-Hardan, N. H., Int. J. Technol. 7 (2015)

19. Andriayani, Raja, S. L., Herlince, S., and Sofyan, N., Int. J. Technol. 7 (2015)

20. Habibah, Z., Arshad, A. N., Ismail, L. N., Bakar, R. A., and Rusop, M., Procedia Eng. 56 (2013) 